\title{
Evaluation of Relationship between Nonalcoholic Fatty Liver and Coronary Artery Disease Severity by Multidetector Computed Tomography
}

\author{
AMIRA A. KHEDR, M.Sc.*; TAYMOUR M. ABDALLAH, M.D.**; SAMEH A. KHODAIR, M.D.* and \\ KHALED I. EL-SHAFEY, M.D.* \\ The Departments of Radiodiagnosis \& Medical Imaging* and Cardiology**, Faculty of Medicine, Tanta University
}

\begin{abstract}
Background: Coronary Heart Disease (CHD) is considered to be a leading cause of morbidity and mortality worldwide, so early detection of CHD in asymptomatic individuals is required. Several metabolic risk factors contribute to development of both Nonalcoholic Fatty Liver Disease (NAFLD) and CHD.
\end{abstract}

Aim of Study: To evaluate the association between (NAFLD) and (CAD) severity.

Material and Methods: This study included thirty patients with symptoms suggestive of ischemic heart disease. All patients were subjected to clinical evaluation, coronary CT angiography and Gensini score was used to assess the coronary artery disease severity. Ultrasound examination of the liver to assess the hepatic steatosis.

Results: Among thirty patients enrolled in our study 13 patients had positive coronary findings 9 of them showed also hepatic steatosis. The association between NAFLD and CAD was significant as regard the age $(p=0.010)$, BMI $(p=0.011)$. And diabetes mellitus $(p=0.011)$. In comparison with the normal group. There was significant association between Gensini score and grading of fatty liver infiltration ( $p$ value $=0.017$ )

Conclusion: There was high prevalence of NAFLD in patients with documented CAD $(69.2 \%)$ with significant association between Gensini score and grading of fatty liver infiltration.

Key Words: Coronary heart disease - Nonalcoholic fatty liver disease-Computed tomography (CT).

\section{Introduction}

THE prevalence and incidence of cardiovascular disease have been known to be associated with the presence of NAFLD [1,2].

However, NAFLD was thought to be a benign condition but now studies reported that NAFLD

Correspondence to: Dr. Amira A. Khedr, The Department of Radiodiagnosis \& Medical Imaging, Faculty of Medicine, Tanta University may progress to cirrhosis, liver failure, and hepatocellular carcinoma [3].

NAFLD is strongly associated to the features of metabolic syndrome and insulin resistance that contribute to development of Coronary Artery Disease (CAD). Thus, it was hypothesized that NAFLD associated CAD [4].

CAD is usually symptomatic; so finding significant relationship between CAD and NAFLD may indicate that screening for NAFLD in patient with CAD has great importance in early diagnosis of the disorder and vice versa [5].

Recently Coronary Computed Tomography Angiography (CCTA) has proven to be effective in evaluation of coronary artery atherosclerosis, including the plaque characteristics and degree of stenosis. Thus, this method can be used to diagnose subclinical atherosclerosis [6,7].

\section{Patients and Methods}

This study was performed in Radiology Department, Tanta University Educational Hospital, during the period from February 2017 to February 2018.

This study included thirty patients; 9 males and 21 females with age ranged from 33 to 78 years (mean age 58 years). All patients were suffering from symptoms suggestive of ischemic heart disease and were referred from Cardiology Department of Tanta University Hospital.

- Committee approval and informed consent were obtained. Inclusion criteria included patients who had symptoms suggestive of ischemic heart disease referred for evaluation by MDCT. 
- Patients with history of Alcohol consumption, history of using agent known to induce fatty liver disease such as steroids, estrogens, aminodarone, tamoxifen, or other chemotherapeutic agents within the previous 6 months and patients who had impaired renal function (creatinine level $\geq 1.8$ $\mathrm{mg} / \mathrm{dl}$ ) were excluded.

All patients were subjected to detailed history taking, clinical examination, laboratory investigations (including serum creatinine ad lipid profile) and radiological examination including:

1- Multislice CT angiography for evaluation of the coronary arteries.

2- Evaluation of the liver by Ultrasound to detect the hepatic steatosis.

\section{CCTA image acquisition and analysis:}

\section{I- Patient preparation:}

A- Detailed explanation of the procedure to all patients with reassurance was done to relief any anxiety.

\section{$B$ - Heart rate control:}

- Heart rate and blood pressure were recorded on arrival to set a baseline for monitoring.

- Patients with heart rate below $65 \mathrm{bpm}$ not given any heart rate control medications. Patients with higher heart rate were given oral $\beta$-blockers provided that there was no contraindication

\section{C- At scanner room:}

- ECG electrodes were applied to chest wall, Brief explanation of the procedure to the patient and reassurance was done to relief any anxiety.

- Breath holding instructions was given to the patients to avoid respiratory motion artifacts.

\section{II- CT scan protocol:}

320-row multidetector CT scanner (Aquilion One, Toshiba Medical Systems, Otawara, Japan) installed at Tanta University Educational Hospital was used for scanning through these steps:

- Initial scanogram was obtained in AP and lateral projection for automatic radiation dose calculation and for planning scan range. The scan started from carina down to the apex of the heart.

- Low-dose unenhanced CT chest scans were done. The images were reviewed on a standard PACS workstation to evaluate the coronary artery calcium scoring.

- Automatic bolus tracking technique was used to detect the arrival of contrast material at descending aorta. In patients with coronary stents, the
ROI was placed at descending aorta at mid heart level with trigger threshold set at 230 repetitive low-dose monitoring examinations $(120 \mathrm{kV}, 50$ $\mathrm{mAs}, 0.5$ second scanning time) were performed 10 seconds after contrast medium injection began. When the trigger threshold was reached, the scan started immediately after breath holding command.

Gensini score was used to determine the coronary artery disease severity, in this scoring system, reduction in the lumen diameter was evaluated. Reductions of $1 \%-25 \%, 26 \%-50 \%, 51 \%-75 \%$, $76 \%-90 \%, 91 \%-99 \%$, and total occlusion were scored as 1, 2, 4, 8, 16, and 32, respectively. Each principal vascular segment was assigned a multiplier that represents its functional importance in maintaining myocardial supply. Multipliers were 5 for the left main coronary artery; 2.5 for the proximal segment of the Left Anterior Descending coronary artery (LAD) and circumflex artery; 1.5 for the mid-segment of the LAD; 1 for the right coronary artery, the distal segment of the LAD, the posterolateral artery, and the obtuse marginal artery; and 0.5 for other segments.

- The severity of the disease was expressed as the sum of the scores for individual lesions. Gensini score and number of stenosed vessels were recorded. Patients with Gensini scores of 20 or more were defined as having severe CAD, which was approximately equal to one stenosed lesion of $70 \%$ or more in the proximal left anterior descending artery.

\section{Ultrasound examination:}

The liver was considered normal if it presented echogenicity equal to that of the kidney (degree $0)$. Fatty infiltration of the liver was described in three levels: Mild (degree 1), when there was a minimum diffuse increase in the hepatic echogenicity, contours of the diaphragm and intrahepatic vessels with normal appearance; moderate (degree 2 ), when there was a moderate diffuse increase in the hepatic echogenicity and a slight deterioration in the image of the vessels of the liver and diaphragm; and severe (degree 3), when there was an apparent increase in the echogenicity. The posterior segment of the right lobe of the liver was difficult to visualize, and the structure of the intrahepatic vessels and contours of the diaphragm were smeared or not viewed.

\section{Statistical analysis:}

Data were fed to the computer and analyzed using IBM SPSS software package Version 20.0. (Armonk, NY: IBM Corp) [8] Qualitative data were 
described using number and percent. The Kolmogorov-Smirnov test was used to verify the normality of distribution quantitative data were described using range (minimum and maximum), mean, standard deviation and median. Significance of the obtained results was judged at the $5 \%$ level. The used tests were:

\section{1- Chi-square test: For categorical variables, to} compare between different groups.

2- Fisher's Exact or Monte Carlo correction: Correction for chi-square when more than $20 \%$ of the cells have expected count less than 5 .

3- ANOVA test: For comparison between each 2 groups was done using Post Hoc Test (Tukey).

\section{Results}

This study included thirty patients 9 of them were males representing $30 \%$ and 21 were females representing $70 \%$ presented by symptoms suggestive of ischemic heart disease referred for evaluation by CCTA during the period between February 2017 and February 2018.

The mean age of the patients was 58 years and ranged from 33 to 78 years.

Table (1): This table demonstrates the distribution of cases according to the finding of coronary CTA and examination of the liver ( $\%$ from row).

\begin{tabular}{|c|c|c|c|c|c|c|c|c|}
\hline & \multicolumn{4}{|c|}{ Liver } & & & \multirow{3}{*}{$x^{2}$} & \multirow{3}{*}{$p$} \\
\hline & \multicolumn{2}{|c|}{ Negative } & \multicolumn{2}{|c|}{ Positive } & \multicolumn{2}{|c|}{ Total } & & \\
\hline & No. & $\%$ & No. & $\%$ & No. & $\%$ & & \\
\hline \multicolumn{9}{|l|}{ Coronary: } \\
\hline Negative & 10 & 58.8 & 7 & 41.2 & 17 & 100.0 & 2.330 & 0.127 \\
\hline Positive & 4 & 30.8 & 9 & 69.2 & 13 & 100.0 & & \\
\hline Total & 14 & 46.7 & 16 & 53.3 & 30 & 100.0 & & \\
\hline
\end{tabular}

From (Table 1) we found that 13 patients out of $30(13 / 30)$ with symptoms suggesting ischemic heart disease had positive coronary atherosclerosis $(43.3 \%) 9$ of them (9/13) had positive liver affection $(69.2 \%)$ and 4 cases $(4 / 13)$ had normal liver $(30.8 \%)$.

Also we found that 17 patients out of $30(17 / 30)$ showing no evidence of coronary atherosclerosis7of them $(7 / 17)$ representing $41.2 \%$ had positive liver affection and 10/17 representing 58.8\% had normal liver.

By another mean we found that 16 patients out of $30(16 / 30)$ had positive liver affection $(53.3 \%)$ and 9 of them (9/16) had coronary artery disease $(56.3 \%)$ and 7 cases $(7 / 16)$ with no evidence of coronary artery disease (43.8\%).

According to the coronary CTA and liver examination we can classify our patients in to four groups:

- Group (A) patients with coronary positive and liver positive findings.

- Group (B) patients with coronary positive and liver negative findings.

- Group (C) patients with liver positive and coronary negative findings.

- Group (D) patients with coronary negative and liver negative findings.

The present study indicated a high prevalence of NAFLD in patients with documented CAD $(69.2 \%)$ as shown in (Table 1$)$.

Table (2): Relation between Gensini score and ultrasound finding of the liver examination $(n=30)$.

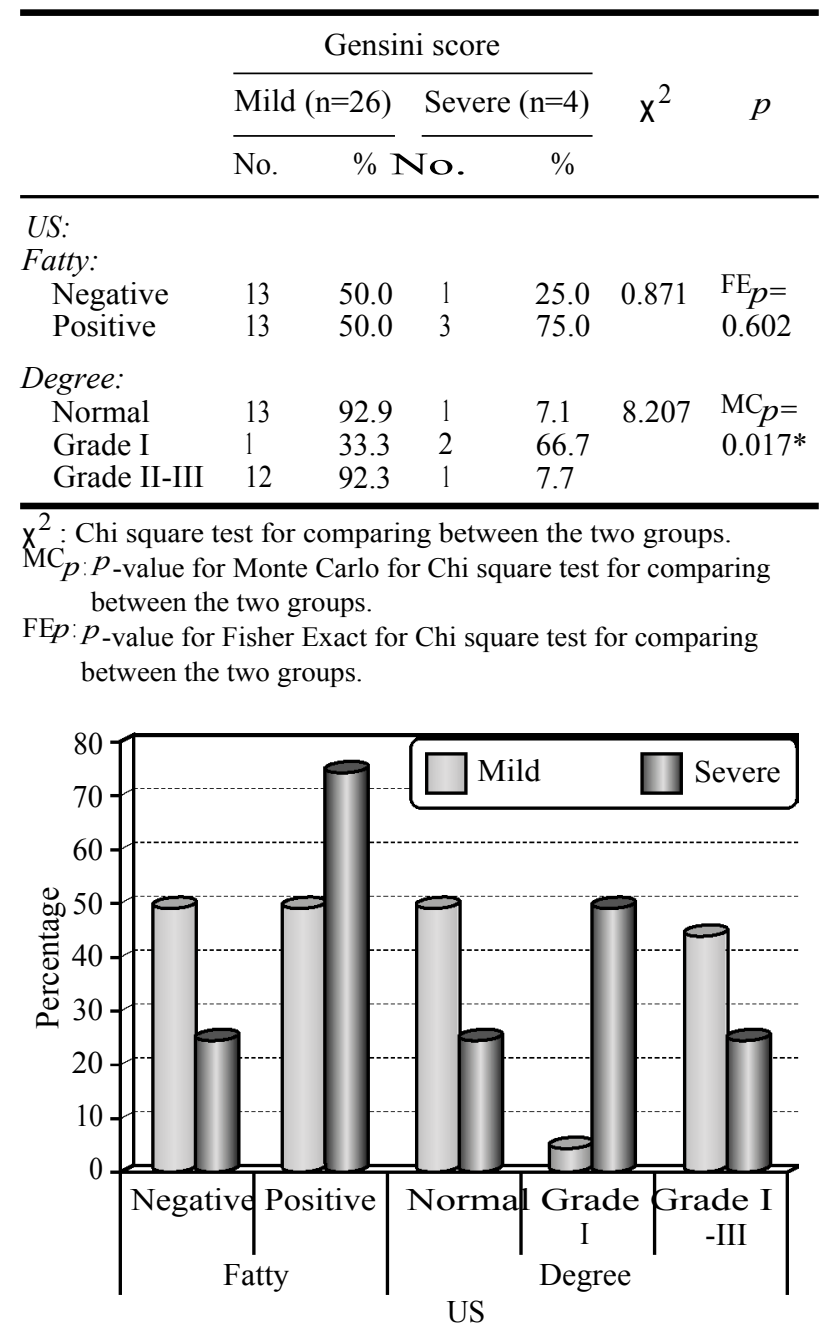

Fig. (1): Relationship between Gensini score and degree of liver affection. 
From (Table 2) and Fig. (1) that demonstrates the relationship between Gensini score and degree of liver affection we found that:

Patients with Gensini score less than 20 (no or mild atherosclerosis) were 26 patients $13(13 / 26)$ of them (representing 50\%) with fatty liver infiltration 12 of them with grade II-III (representing $92.2 \%$ from patients with grade II-III).
Patients with Gensini score more than 20 (severe atherosclerosis) were 4 patients 2 (2/4) of them with mild fatty liver infiltration and 1 of them (1/4) with grade II-III.

There was significant association between Gensini score and grading of fatty liver infiltration ( $p$-value $=0.017)$.

Table (3): Comparison between the different studied groups according to BMI $\left(\mathrm{kg} / \mathrm{m}^{2}\right)$.

\begin{tabular}{|c|c|c|c|c|c|c|c|c|}
\hline & \multicolumn{2}{|c|}{$\begin{array}{l}\text { Coronary +ve \& } \\
\text { Liver +ve } \\
(n=9)\end{array}$} & \multicolumn{2}{|c|}{$\begin{array}{l}\text { Coronary -ve \& } \\
\text { Liver +ve } \\
(\mathrm{n}=7)\end{array}$} & \multicolumn{4}{|c|}{$\begin{array}{cc}\text { Coronary +ve \& } & \text { Coronary -ve \& } \\
\text { Liver - ve } & \text { Liver - ve } \\
(\mathrm{n}=4) & (\mathrm{n}=10)\end{array}$} \\
\hline & No. & $\%$ & No. & $\%$ & No. & $\%$ & No. & $\%$ \\
\hline \multicolumn{9}{|l|}{$B M I\left(\mathrm{~kg} / \mathrm{m}^{2}\right):$} \\
\hline Normal (18.5-24.9) & 0 & 0.0 & 0 & 0.0 & 0 & 0.0 & 1 & 10.0 \\
\hline Overweight (25-29.9) & 4 & 44.4 & 1 & 14.3 & 0 & 0.0 & 6 & 60.0 \\
\hline Obese (30-34.9) & 3 & 33.3 & 5 & 71.4 & 4 & 100.0 & 3 & 30.0 \\
\hline Severely obese (35-39.9) & 1 & 11.1 & 1 & 14.3 & 0 & 0.0 & 0 & 0.0 \\
\hline Morbidly obese $(>40)$ & 1 & 11.1 & 0 & 0.0 & 0 & 0.0 & 0 & 0.0 \\
\hline Min.-max. & \multicolumn{2}{|c|}{$28.20-44.40$} & \multicolumn{2}{|c|}{$29.40-36.60$} & \multicolumn{2}{|c|}{$31.60-34.60$} & \multicolumn{2}{|c|}{$23.0-32.0$} \\
\hline Mean \pm SD. & \multicolumn{2}{|c|}{$32.61 \pm 5.04$} & \multicolumn{2}{|c|}{$33.23 \pm 2.33$} & \multicolumn{2}{|c|}{$32.80 \pm 1.28$} & \multicolumn{2}{|c|}{$28.26 \pm 2.75$} \\
\hline Median & \multicolumn{2}{|c|}{30.50} & \multicolumn{2}{|c|}{33.90} & \multicolumn{2}{|c|}{32.50} & \multicolumn{2}{|c|}{28.25} \\
\hline $\mathrm{F}(p)$ & \multicolumn{8}{|c|}{$4.013^{*}(0.018 *)$} \\
\hline Significance between the groups & \multicolumn{8}{|c|}{$p_{1}=0.928, p_{2}=0.725, p_{3}=0.011^{*}, p_{4}=0.844, p_{5}=0.035, p_{6}=0.007^{*}$} \\
\hline
\end{tabular}

F, $p: \mathrm{F}$ and $p$-values for ANOVA test, pairwise comparison bet. Each 2 groups was done using Post Hoc Test (Tukey).

$p_{1}: p$-value for comparing between coronary $+\mathrm{ve} \&$ liver $+\mathrm{ve}$ and coronary $-\mathrm{ve} \&$ liver $+\mathrm{ve}$.

$p_{2}: p$-value for comparing between coronary $+\mathrm{ve} \&$ liver +ve and coronary $+\mathrm{ve} \&$ liver $-\mathrm{ve}$

$p_{3}: p$-value for comparing between coronary +ve \& liver +ve and coronary $-\mathrm{ve} \&$ liver $-\mathrm{ve}$.

$p_{4}: p$-value for comparing between coronary $-\mathrm{ve} \&$ liver $+\mathrm{ve}$ and coronary $+\mathrm{ve} \&$ liver $-\mathrm{ve}$

$p_{5}: p$-value for comparing between coronary $-\mathrm{ve} \&$ liver $+\mathrm{ve}$ and coronary $-\mathrm{ve} \&$ liver $-\mathrm{ve}$.

$p_{*} 6: p$-value for comparing between coronary +ve \& liver -ve and coronary -ve \& liver -ve.

: Statistically significant at $p \leq 0.05$.

From (Table 3) we found that:

- The mean BMI was 30.5 and ranging from 28.2 to 44.4 .

- BMI was statistically significantly in:

- Group A showing positive coronary and liver findings compared to group D (normal group) (value $=0.011)$.

- Group C showing positive liver findings only compared to group $\mathrm{D}$ (normal group) ( $p$-value= $0.035)$.

- Group B showing positive coronary findings and normal liver compared to group $\mathrm{D}$ ( $p$-value $=$ 0.007).
Also we found that:

Diabetes mellitus was statistically significant in:

- Group A that had positive coronary and liver finding compared to group D (normal group) (value $=0.011)$.

- There is no significance in comparison between the groups as regard the dyslipidemia and hypertension.

\section{Illustrated cases:}

Case (1): Diabetic female patient aged 60 years old presented by chest that increased by effort: Showing coronary vascular affection and fatty liver. 


\section{Multidetector coronary CT angiography findings:}
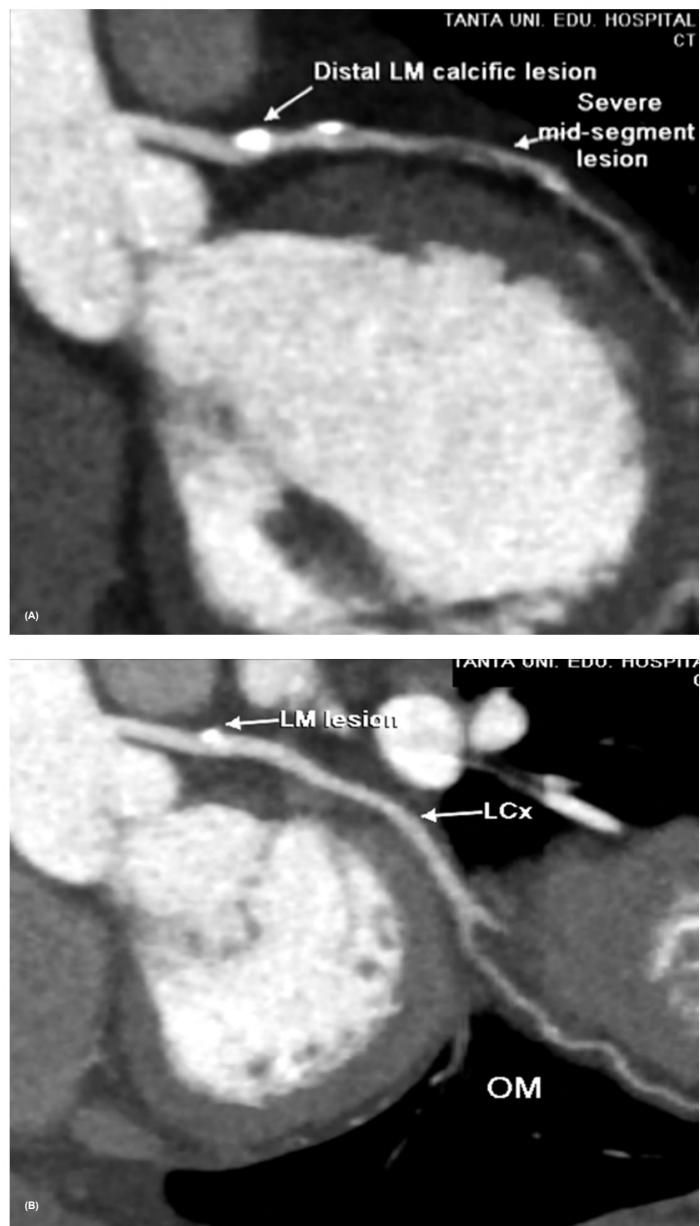

Fig. (A,B): Left anterior oblique Maximum Intensity Projection images (MIP) showing calcific lesion at the distal Left Main (LM) artery exerting mild stenosis measured about $5.5 \mathrm{~mm}$ in length. Mixed lesion at the proximal segment of Left Anterior Descending artery (LAD) exerting 50\% stenosis measured about $8 \mathrm{~mm}$ in length. Another soft lesion seen at the distal segment of the LAD artery exerting severe stenosis measured about $10 \mathrm{~mm}$ in length.

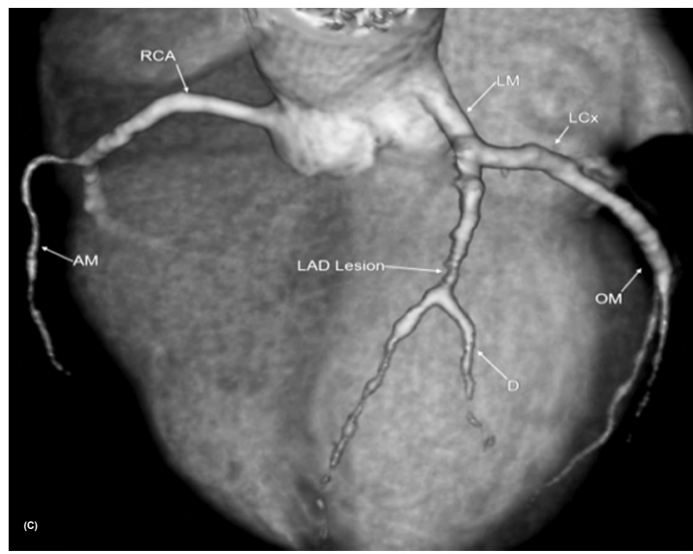

Fig. (C): 3D Volume Rendering (VR) showing severe stenosis of the distal LAD artery.

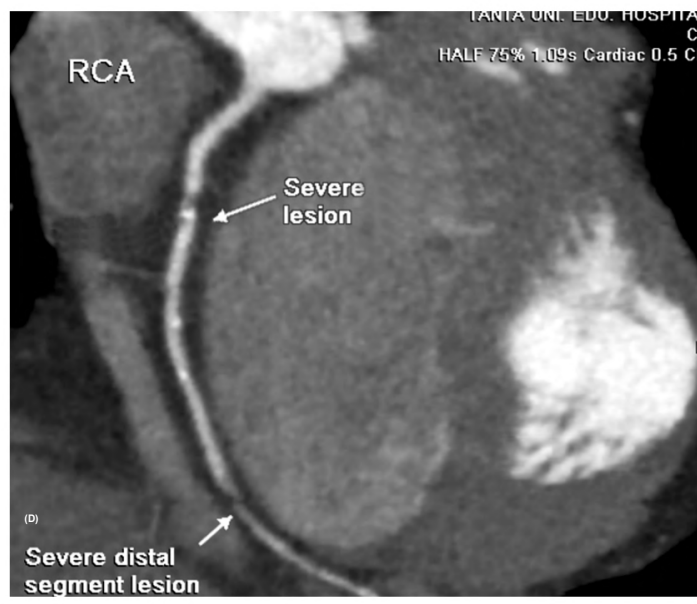

Fig. (D): Curved Multiplanar Reformation (MPR) image showing mixed lesion at the proximal segment of the Righ Coronary Artery (RCA) exerting severe stenosis about $70 \%$, another mixed lesion at the mid segment exerting moderate stenosis about $50 \%$ measured about $3.5 \mathrm{~mm}$ in length.

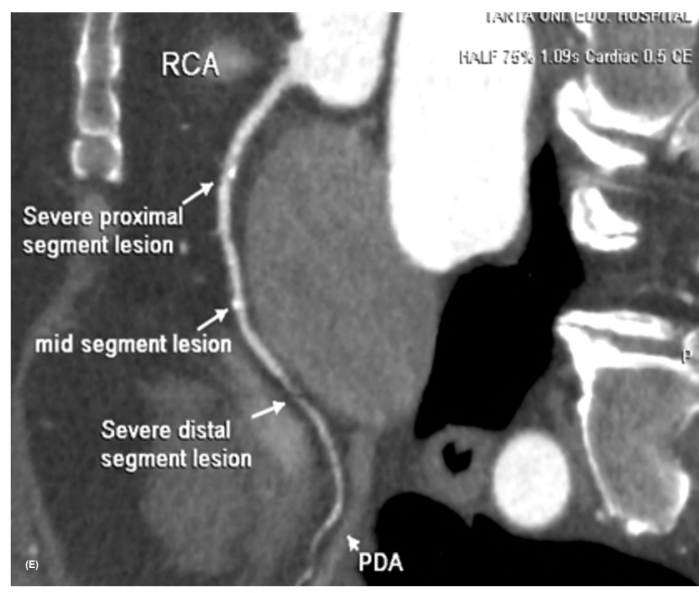

Fig. (E): Curved MPR reformatting image soft lesion seen at the distal segment of RCA exerting severe stenosis and measured about $7.5 \mathrm{~mm}$ in length.

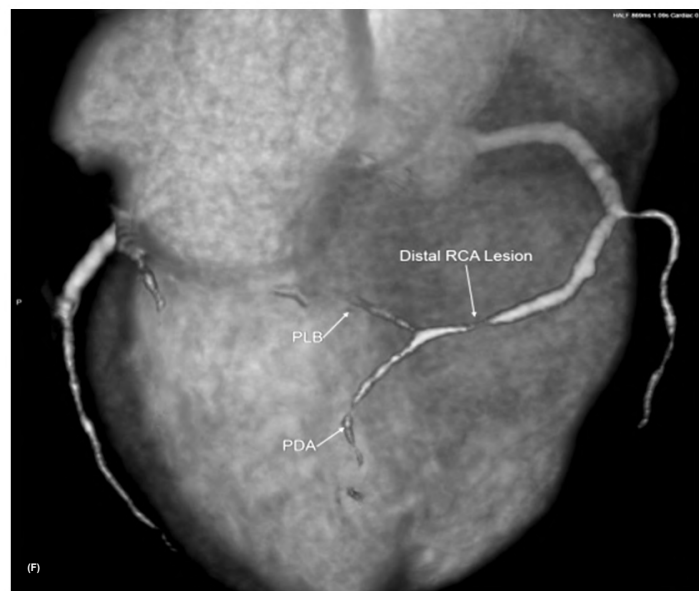

Fig. (F): 3D (VR) showing severe stenosis of the distal RCA artery. 


\section{Gensini score:}

29 which means severe atherosclerosis.

\section{Ultrasound flinging:}

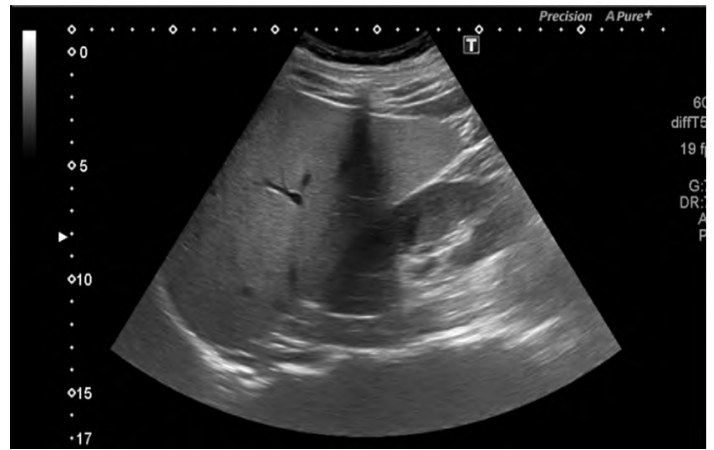

Sagittal image on the liver showing minimum diffuse increase in the hepatic echogenicity compared to the right kidney, the contours of the diaphragm and intrahepatic vessels with normal appearance...grade I fatty liver (mild hepatic steatosis).

Case (2): Hypertensive male patient aged 78 years old presented by atypical chest pain showing: Coronary vascular affection and hepatic steatosis.

\section{Multidetector coronary CT angiography findings:}
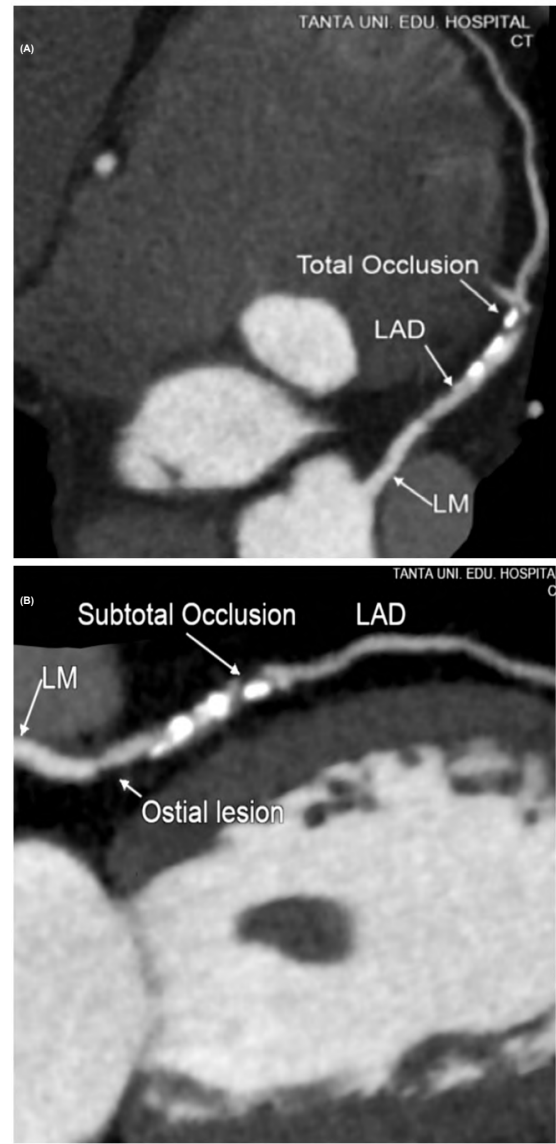

Fig. (A,B): Curved MPR images showing calcific lesion at the proximal segment of (LAD) artery exerting moderate stenosis measured about $7 \mathrm{~mm}$ in length.
Another mixed lesion seen at the mid segment of the LAD artery exerting subtotal occlusion measured about $12 \mathrm{~mm}$ in length.

(B): Left anterior oblique MIP image showing ostial soft lesion at the LAD artery exerting moderate stenosis measured about $4 \mathrm{~mm}$.

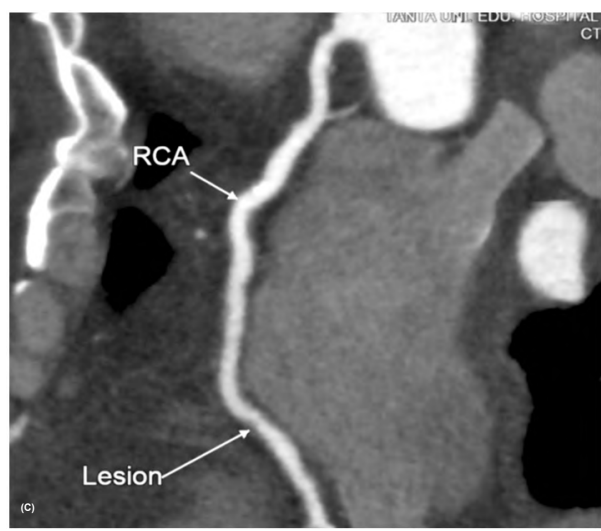

Fig. (C): Curved MPR image showing mixed lesion seen at the distal segment of the RCA artery exerting moderate stenosis about $60 \%$.

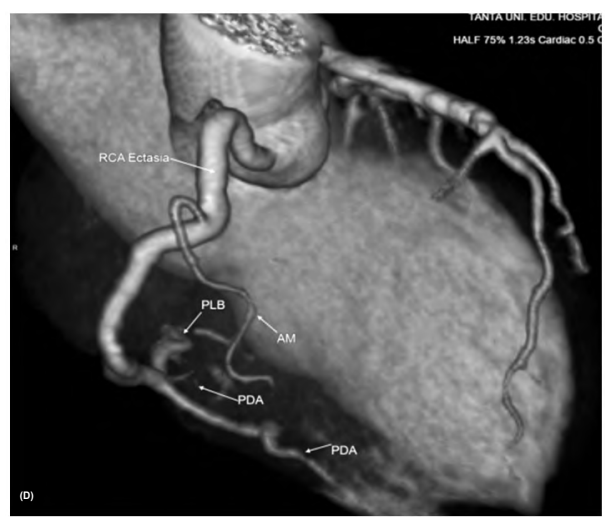

Fig. (D): 3D (VR) showing ectasia of the RCA artery.

Gensini score:

42 which means severe atherosclerosis.

\section{Ultra sound flinging:}

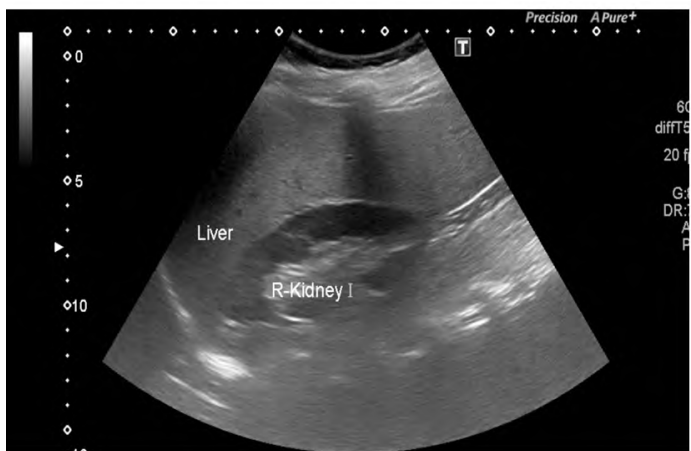

Sagittal image on the liver showing minimum diffuse increase in the hepatic echogenicity compared to the right kidney, the contours of the diaphragm and intrahepatic vessels with normal appearance...grade I fatty liver (mild hepatic steatosis). 


\section{Discussion}

In this study, we focused on the association between NAFLD and coronary artery disease severity and our main findings were as follow:

1- There was high prevalence of NAFLD in patients with documented CAD (69.2\%).

2- The association between NAFLD and CAD was significant as regard the age, BMI and diabetes mellitus in comparison with the normal group.

3- There is significant association between Gensini score and grading of fatty liver infiltration ( $p$ value $=0.017$ ).

We found fatty liver disease in $69.2 \%$ of the patients with documented CAD that came in agreement with Baharvandi et al., [4] whose study showed that NAFLD can be detected in high percentage of patients with documented CAD (47\%), also Adibi A et al., [5] found that the prevalence of NAFLD in CAD patients was higher than the control group. Indicating that Increase in the prevalence of NAFLD can lead to the increase in cardiovascular diseases. Wong et al., [9] showed that fatty liver was associated with CAD (64.7\% of the patient with documented CAD), also that was in concurrent to the study performed by Sun and $\mathrm{Lu}$ [10]. That showed that fatty liver was associated with CAD (64.7\%).

- We also found that there was significant association between Gensini score and grading of fatty liver infiltration ( $p$-value $=0.017)$. That agreed with Alper et al., [11] who observed that patients with NAFLD had significantly higher scores for the severity of CAD as evaluated by the Gensini score than patients without NAFLD $(p<0.001)$. The presence of NAFLD and the degree of NAFLD were significantly correlated with the severity score of CAD. Also Kim et al., [12] who found that the prevalence of CAC significantly increased with severity of NAFLD and Açikel et al., [13] who concluded that the presence of steatosis in the US and its severity may represent an independent effect in both the presence and severity of CAD.

- We found that BMI was statistically significantly in Group A showing positive coronary and liver findings compared to Group D (normal group) $(p$-value $=0.011)$ and in Group $\mathrm{C}$ showing positive liver findings only compared to Group D (normal group $)(p$-value $=0.035)$ this was in agree with Baharvand et al., [4]. Who found that mean BMI was significantly higher in patients with fatty liver disease compared to those without liver affection $(p=0.005)$, but not in agree with Sun and $\mathrm{Lu}[10]$ and Açikel et al., [13] as they didn't found significant relation to the BMI.

- Also we found that $26.7 \%$ of the cases were diabetic and $62.5 \%$ of the diabetic cases had association between the NAFLD and CHD with significant relationship compared to the normal group (value $=0.011$ ). This was in line with Kwak et al., [14] and Targher et al., [15]. As they found that presence of NAFLD is associated with CHD in subjects with DM, whereas Baharvand et al., [4] and Mc Kimmie et al., [16] did not found the relationship between fatty liver disease and CHD in diabetic patients.

\section{Conclusion:}

In this study, we focused on the association between NAFLD and coronary artery disease severity and our main findings were as follow:

1 - There was high prevalence of NAFLD in patients with documented CAD (69.2\%).

2- The association between NAFLD and CAD was significant as regard the age, BMI and diabetes mellitus in comparison with the normal group.

3- There was significant association between Gensini score and grading of fatty liver infiltration $(p$-value $=0.017)$.

4- The present study along with previous reports may indicate the importance of screening for NAFLD in patient with CAD and vice versa.

\section{Competing interests:}

The authors declare that they have no competing interests.

\section{References}

1- ONI E.T., AGATSTON A.S., BLAHA M.J., et al.: Burden and severity of subclinical cardiovascular disease among those with nonalcoholic fatty liver; should we care? Atherosclerosis, 230 (2): 258-67, 2013.

2- SINN D.H., KANG D., CHANG Y., et al.: Non-alcoholic fatty liver disease and progression of coronary artery calcium score. Gut., 66 (2): 323-9, 2017.

3- PASCHOS P. and PALETAS K.: Non-alcoholic fatty liver disease and metabolic syndrome. Hippokratia, 13 (1): 919, 2009.

4- BAHARVAND-AHMADI B., SHARIFI K. and NAMDARI M.: Prevalence of non-alcoholic fatty liver disease in patients with coronary artery disease. ARYA Atheroscler, 12 (4): 201-5, 2016.

5- ADIBI A., ANSARI M.G., DALILI A.R., et al.: Association between Nonalcoholic Fatty Liver Disease (NAFLD) and Coronary Artery Disease (CAD) in Patients with Angina Pectoris. Open Journal of Medical Imaging, 3 (3): $97-$ 101, 2013. 
6- PARK G.M., YUN S.C., CHO Y.R., GIL E.H., HER S.H., et al.: Prevalence of coronary atherosclerosis in an Asian population: Findings from coronary computed tomographic angiography. Int. J. Cardiovasc. Imaging, 31 (3): 659-68, 2015.

7- VILAR C.P., COTRIM H.P., FLORENTINO G.S., et al.: Association between nonalcoholic fatty liver disease and coronary artery disease. Rev. Assoc. Med. Bras., 59 (3): 290-7, 2013.

8- KIRKPATRICK L.A. and FEENEY B.C.: A simple guide to IBM SPSS statistics for Version 20.0. Student ed. Belmont, Calif.: Wadsworth, Cengage Learning, 2013.

9- WONG V.W., WONG G.L., YIP G.W., et al.: Coronary artery disease and cardiovascular outcomes in patients with non-alcoholic fatty liver disease. Gut., 60 (12): 17217, 2011.

10- SUN L. and LU S.: Association between non-alcoholic fatty liver disease and coronary artery disease severity. Chin. Med. J., 124 (6): 867-72, 2011.

11- ALPER A.T., HASDEMIR H., SAHIN S., et al.: The relationship between nonalcoholic fatty liver disease and the severity of coronary artery disease in patients with metabolic syndrome. Turk. Kardiyol. Dern. Ars., 36 (6): 376-81, 2008
12- KIM M.K., AHN C.W., NAM J.S., et al.: Association between nonalcoholic fatty liver disease and coronary artery calcification in postmenopausal women. Menopause, 22 (12): 1323-7, 2015.

13-AÇIKEL M., SUNAY S., KOPLAY M., et al.: Evaluation of ultrasonographic fatty liver and severity of coronary atherosclerosis, and obesity in patients undergoing coronary angiography. Anadolu. Kardiyol. Derg., 9 (4): 2739, 2009.

14- KWAK M.S., YIM J.Y., KIM D., et al.: Nonalcoholic fatty liver disease is associated with coronary artery calcium score in diabetes patients with higher HbA1c. Diabetol. Metab. Syndr., 7: 28, 2015.

15- TARGHER G., BERTOЫNI L., RODELLA S., et al.: Nonalcoholic fatty liver disease is independently associated with an increased incidence of cardiovascular events in type 2 diabetic patients. Diabetes Care, 30 (8): 2119-21, 2007.

16- McKIMMIE R.L., DANIEL K.R., CARR J.J., et al.: Hepatic steatosis and subclinical cardiovascular disease in a cohort enriched for type 2 diabetes: The Diabetes Heart Study. Am. J. Gastroenterol., 103 (12): 3029-35, 2008. SHARMA U.K. and SHRESTHA D.: Musculoskeletal ultrasound: Is it underutilised? Kathmandu University Medical Journal, 5: 552-6, 2007.

\section{تقييم العلاقة بين الكبد الدهنى غير الكحولى وشلدة الإصابة الكابية

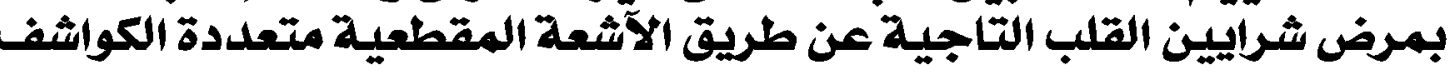

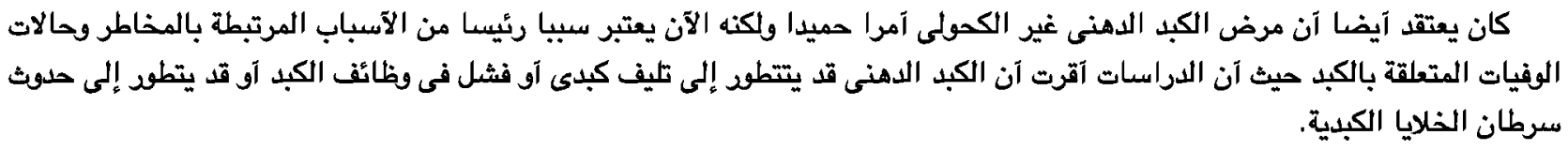

قد آقترحت سلسلة من الدراسات السابقة آن مرض الكبد الدهنى غير الكحولى مرتبط بمرض شرئ الإيين القلب التاجية بغض النظل عن العوامل

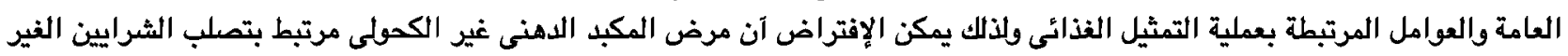
مشخص إكلينكيا.

$$
\begin{aligned}
& \text { تهدف الدراسة التى نقوم بها على تقيم العلاقة بين مرض الكبد الدهنى غير الكحولى وشدة الإصابة بمرض شرايين القلب التاجية. } \\
& \text { ويعد دراسة الموضوع تبين آن الكبد الدهنى غير الكحولى يمثل ؟ .97\% من الحالات التى وجد آنها مصابة بمرض تصلب شرايين القلب }
\end{aligned}
$$

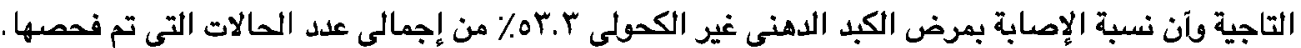

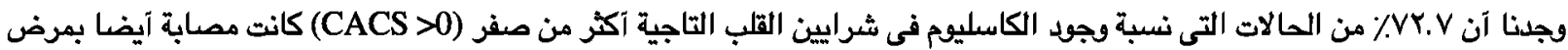
الكبد الدهنى غير الكحولى، كما آنتا وجدنا علاقة ذات آهمية بين شدة الإصابة بمرض شرايين القلب التاجية بإستخدام (Gensini Score) ودرجة ترسب الدهون فى الكبد.

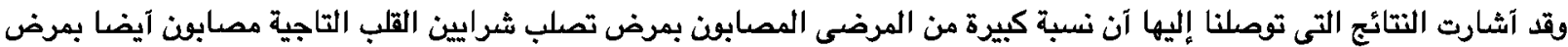

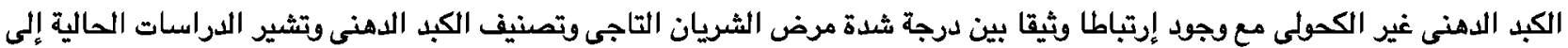

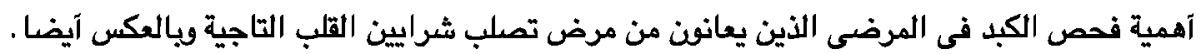

